\title{
Are the First and Second Hip in Staged Bilateral Total Hip Arthroplasty Equal? A Hospital Adverse Event and Perioperative Risk Comparison
}

\author{
Jesus M. Villa, MD ${ }^{1}$ Tejbir S. Pannu, MD, MS ${ }^{1}$ Carlos A. Higuera, MD ${ }^{1}$ Juan C. Suarez, MD² \\ Preetesh D. Patel, MD ${ }^{1}$ Wael K. Barsoum, MD ${ }^{1}$ \\ ${ }^{1}$ Levitetz Department of Orthopaedic Surgery, Cleveland Clinic \\ Florida, Weston, Florida \\ 2 Miami Orthopedics \& Sports Medicine Institute, Baptist Health South \\ Florida, Coral Gables, Florida

\begin{abstract}
Address for correspondence Carlos A. Higuera, MD, Levitetz Department of Orthopaedic Surgery, Cleveland Clinic Florida, 2950 Cleveland Clinic Blvd, Weston, Florida 33331-3609
\end{abstract} \\ (e-mail: higuerc@ccf.org).
}

J Hip Surg 2021;5:91-95.

\begin{abstract}
Keywords

- hospital adverse events

- bilateral total hip arthroplasty

- perioperative outcomes

- staged

- first hip

- second hip

Hospital adverse events remain a significant issue; even "minor events" may lead to increased costs. However, to the best of our knowledge, no previous investigation has compared perioperative events between the first and second hip in staged bilateral total hip arthroplasty (THA). In the current study, we perform such a comparison. A retrospective chart review was performed on a consecutive series of 172 patients (344 hips) who underwent staged bilateral THAs performed by two surgeons at a single institution (2010-2016). Based on chronological order of the staged arthroplasties, two groups were set apart: first-staged THA and second-staged THA. Baseline-demographics, length of stay (LOS), discharge disposition, hospital adverse events, and hospital transfusions were compared between groups. Statistical analyses were performed using independent $t$-tests, Fisher's exact test, and/or Pearson's chi-squared test. The mean time between staged surgeries was 465 days. There were no significant differences in baseline demographics between first-staged THA and second-staged THA groups (patients were their own controls). The mean LOS was significantly longer in the first-staged THA group than in the second ( 2.2 vs. 1.8 days; $p<0.001$ ). Discharge (proportion) to a facility other than home was noticeably higher in the first-staged THA group, although not statistically significant (11.0 vs. $7.6 \% ; p=0.354$ ). The rate of hospital adverse events in the first-staged THA group was almost twice that of the second ( $37.2 \mathrm{vs.} 20.3 \% ; p=0.001$ ). There were no significant differences in transfusion rates. However, these were consistently better in the second-staged THA group. When compared with the first THA, our findings suggest overall shorter LOS and fewer hospital adverse events following the second.

Level of Evidence Level III.
\end{abstract}

In the face of bilateral hip osteoarthritis requiring bilateral total hip arthroplasty (THA), surgeries can be performed either simultaneously (same anesthesia) or in a staged manner (different hospitalizations). ${ }^{1-3}$ There is still controversy on the best method of approach for bilateral surgeries; multiple investigations have been attempted to settle this issue. ${ }^{3-6}$ However, to the best of our knowledge, no previous study has examined the differences, if any, on perioperative hospital adverse events between the first and second hip in staged bilateral THA. received

April 17, 2020

accepted after revision

January 25, 2021

published online

June 15, 2021 (c) 2021. Thieme. All rights reserved.

Thieme Medical Publishers, Inc., 333 Seventh Avenue, 18th Floor, New York, NY 10001, USA
DOI https://doi.org/

10.1055/s-0041-1729868. ISSN 2472-8446. 
It is important to note that this study is not about differences in complications between the stages of bilateral THA. It is about hospital adverse events, including "minor events," which usually are not considered as complications or noted in most publications. We attempted to evaluate the full spectrum of events regardless of their impact or weight on outcomes. The impact of minor events is lower, but due to their high frequency, the overall negative impact may be significant. Single major episodes (that occur rarely) do not properly represent the full impact of hospital adverse events. Even "minor events" such as fever or tachycardia may lead to increased costs due to workup tests, interconsultations, and/or increased hospital length of stay (LOS) ${ }^{4,7,8}$ Most orthopaedic studies rarely analyze "minor events" such as nausea or vomiting. ${ }^{9,10}$ This part of the safety spectrum has been neglected. To the best of our knowledge, no previous investigation has determined all hospital adverse events in the first and second stages of bilateral THA. Therefore, we sought to compare (1) hospital LOS, (2) discharge disposition, and (3) rates of hospital adverse events and transfusions (total and allogeneic only) between the first and second hip in staged bilateral THA.

\section{Materials and Methods}

A retrospective chart review was performed on a consecutive series of 172 patients who underwent staged bilateral THAs (344 hips) performed by two fellowship trained orthopaedic surgeons at a single institution between November 2010 and July 2016. Two groups were set apart based on the chronological order of the staged arthroplasties: (1) first THA $(n=172)$ and (2) second THA $(n=172)$. All hip systems were US Food and Drug Administration (FDA) approved for the uses described. Institutional review board approval was obtained for this investigation. Baseline demographics included age, sex (female vs. male), race (white, black, other), ethnicity (non-Hispanic vs. Hispanic), body mass index (BMI), ${ }^{11}$ American Society of Anesthesiologists (ASA) physical status classification system, ${ }^{12}$ preoperative diagnosis (primary vs. secondary osteoarthritis), and surgical approach (anterior vs. posterior) that were collected from our electronic medical records system and compared between both groups.

\section{Outcome Measures}

Perioperative outcome measures studied included hospital LOS, discharge disposition (home vs. other), hospital transfusions (all types and allogeneic only, yes or no), and hospital adverse events (presence of any event, yes or no; allinclusive: that is, fever, nausea, confusion, pulmonary embolism). Hospital adverse events were defined as any untoward medical occurrence during hospitalization as noted in medical records. In each patient, one author reviewed the following parts of the electronic chart: demographics, operative report, anesthesia intraoperative report, blood bank transfusion report (if any), progress notes of each day after surgery, and hospital discharge summary. All hospital adverse events noted in medical records were collected as written and subsequently analyzed. Consequently, an adverse event could range from a minor one such as fever or nausea to a more life-threatening event such as pulmonary embolism. All hospital adverse events were subcategorized into major- or minor-based on severity and subsequent required interventions as described by Higuera et $\mathrm{al}^{9}$ and Pulido et al. ${ }^{10}$

\section{Statistical Analysis}

Categorical variables (sex, race, ethnicity, ASA, hospital adverse events, transfusions) were described with numbers and percentages and compared using Pearson's chi-squared and/or two-tailed Fisher's exact tests. Noteworthy, only the presence (yes) or not (no) of any hospital adverse event was accounted for the statistical comparisons between both groups. For example, if a patient was transfused because of postoperative anemia and also experienced hypotension, nausea, this case was computed as a "yes" only once. Likewise, if a patient only had a single episode of nausea, it was also computed as a "yes." Continuous variables (age, BMI, and LOS) were compared using two-tailed independent $t$-tests. Statistical analyses were performed using Statistical Package for Social Sciences (SPSS) version 24 (IBM Corporation, Armonk, NY). Alpha was set at $p<0.05$.

\section{Results}

The mean time between staged surgeries was 465 days ( \pm standard deviation 407 days; range, 49-1,743 days). There were no significant differences in baseline demographics that might have changed between the first and second hip (as patients served as their own controls) (-Table 1). The mean LOS was significantly longer in the firststaged THA group when compared with the second THA group ( 2.2 vs. 1.8 days, respectively; $p<0.001$ ). The proportion of patients discharged to a facility other than home was noticeably higher in the first hip group, although the difference was not statistically significant (11.0 vs. $7.6 \%$, respectively; $p=0.354$ ). The rate of hospital adverse events in the first hip group was almost twice the one of the second (37.2 vs. $20.3 \%$, respectively; $p=0.001)$. There were no significant differences on transfusion rates. However, these were consistently better in the second THA group (-Table 2 ). The most frequent hospital adverse event found in the entire series was acute postoperative anemia secondary to blood loss requiring transfusion $(n=30)$ followed by electrolyte imbalance $(n=28)$ and hypotension $(n=26)$. In the first THA group, electrolyte imbalance $(n=21)$ was the most common adverse event, while in the second, it was hypotension $(n=12)$ (-Table 3).

\section{Discussion}

The presence of hospital adverse events (even "minor events" such as fever or nausea) may lead to substantial expenses and/or increased hospital stay. On the other hand, to the best of our knowledge, no previous study has evaluated possible differences on perioperative outcomes or hospital adverse 
Table 1 Baseline demographics and characteristics of the first THA and the staged second THA groups from the series of staged bilateral THA cases $(n=344)$

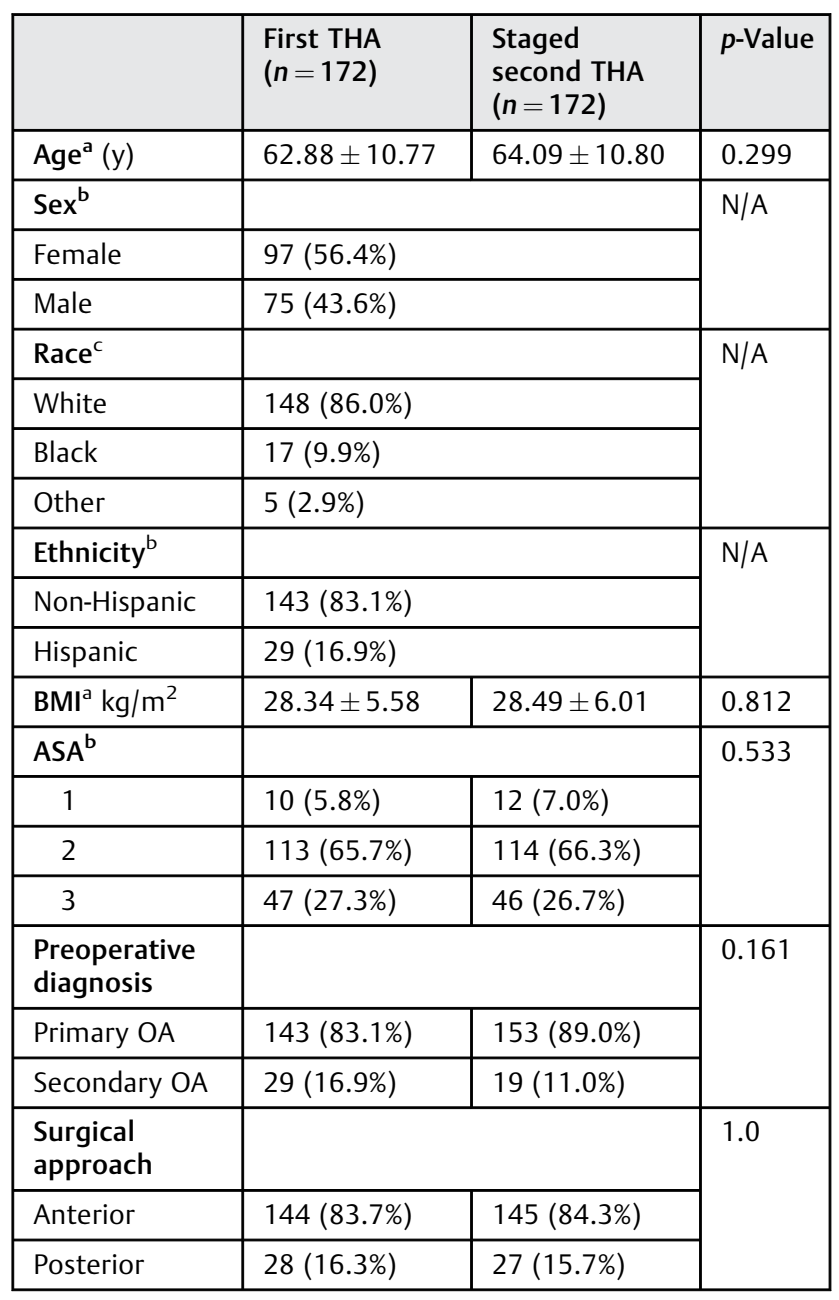

Abbreviations: ASA, American Society of Anesthesiologists; BMI, body mass index; OA, osteoarthritis; THA, total hip arthroplasty.

${ }^{a}$ Mean \pm standard deviation.

${ }^{\mathrm{b}}$ Number of cases (percentages) within groups.

${ }^{\mathrm{C}}$ Available data.

events between the first and second hip in staged bilateral THA. Therefore, we sought to compare (1) hospital LOS, (2) discharge disposition, and (3) rates of hospital adverse events and transfusions (total and allogeneic only) between the first and second hip in staged bilateral THA.

This investigation should be viewed in light of certain limitations. First, it is a retrospective study. However, all cases were performed consecutively by two adult reconstructive orthopaedic surgeons at a single institution and in a standard fashion. This context helps mitigate the possibility of bias. Second, our study evaluated a relatively small number of procedures. Nevertheless, we performed a direct chart review of each case and this methodology allowed for better granularity and identification of the outcomes of interest in contrast to larger studies that rely exclusively on administrative databases ${ }^{13-15}$ that are unable to capture the full spectrum of adverse events. Third, the rates of blood transfusions were high. Some cases predate the use of
Table 2 Perioperative outcomes of first THA and the staged second THA groups from the series of staged bilateral THA cases $(n=344)$

\begin{tabular}{|c|c|c|c|}
\hline & $\begin{array}{l}\text { First THA } \\
(n=172)\end{array}$ & $\begin{array}{l}\text { Staged } \\
\text { second THA } \\
(n=172)\end{array}$ & $p$-Value \\
\hline Length of stay $(d)^{a}$ & $2.2 \pm 1.0$ & $1.8 \pm 1.0$ & $<0.001$ \\
\hline $\begin{array}{l}\text { Discharge } \\
\text { disposition }^{\text {b }}\end{array}$ & & & \multirow[t]{3}{*}{0.354} \\
\hline Home & $153(89.0 \%)$ & 159 (92.4\%) & \\
\hline $\begin{array}{l}\text { Other (that is, } \\
\text { extended } \\
\text { care facility) }\end{array}$ & $19(11.0 \%)$ & $13(7.6 \%)$ & \\
\hline $\begin{array}{l}\text { Hospital adverse } \\
\text { event rate }^{\mathrm{b}}\end{array}$ & $64(37.2 \%)$ & 35 (20.3\%) & 0.001 \\
\hline $\begin{array}{l}\text { Transfusion rate } \\
\text { (all types) }^{\mathrm{b}}\end{array}$ & $19(11.0 \%)$ & $11(6.4 \%)$ & 0.180 \\
\hline $\begin{array}{l}\text { Allogeneic } \\
\text { transfusion rate }\end{array}$ & $15(8.7 \%)$ & $10(5.8 \%)$ & 0.407 \\
\hline
\end{tabular}

Abbreviation: THA, total hip arthroplasty.

${ }^{\mathrm{a}}$ Mean \pm standard deviation.

${ }^{\mathrm{b}}$ Number of cases (percentages) within groups.

tranexamic acid and this circumstance might explain the relatively high rate of transfusions in both groups. Regarding autologous transfusions, a practice now abandoned, it is important to note that just five patients had this type of transfusion, a small proportion (1.45\%) in the whole series (5/344). Fourth, the effect of time could have influenced the results and be a source of bias. However, the mean time between staged surgeries was 465 days and during such period of time any great and rapid changes in protocols did not take place in our hospital. Outpatient THA was not performed during the study period. Further, we evaluated basic patient characteristics that could vary from stage to stage such as age, BMI, ASA, surgical approach, and preoperative diagnosis and did not find statistically significant differences between our two stage groups. Finally, we did not evaluate patient satisfaction. We consider that further investigations on the possible associations between hospital adverse events (particularly "minor events") and patient satisfaction are also warranted as some particular "minor events" (that is, nausea, dizziness) could have larger detrimental effects than others.

After a thorough literature review in PUBMED concerning differences on perioperative outcomes or hospital adverse events between the first and second hip in staged bilateral THA, we were unable to find a single investigation addressing this issue. Our data showed that LOS was significantly longer in the first-staged THA. A plausible explanation could be that patients undergoing the second THA already have, from the first surgery, a better understanding of postoperative protocols and rehabilitation regimen. Undergoing the first THA certainly informs the patient about what to expect from the second one. Concerning discharge disposition, we found no statistically significant differences between our two groups. 
Table 3 Incidence of hospital adverse events in the entire cohort of cases, the first total hip arthroplasty (THA) group, and the second THA group

\begin{tabular}{|c|c|c|c|}
\hline Event description & $\begin{array}{l}\text { Entire } \\
\text { cohort } \\
(n=344)\end{array}$ & $\begin{array}{l}\text { First THA } \\
(n=172)\end{array}$ & $\begin{array}{l}\text { Staged } \\
\text { second THA } \\
(n=172)\end{array}$ \\
\hline \multicolumn{4}{|l|}{ Minor events } \\
\hline $\begin{array}{l}\text { Acute postoperative } \\
\text { anemia secondary to } \\
\text { blood loss requiring } \\
\text { transfusion }\end{array}$ & 30 & 19 & 11 \\
\hline $\begin{array}{l}\text { Electrolyte imbalance } \\
\text { (hypokalemia, } \\
\text { hyponatremia) }\end{array}$ & 28 & 21 & 7 \\
\hline Hypotension & 26 & 14 & 12 \\
\hline Hypovolemia & 15 & 9 & 6 \\
\hline Fever & 10 & 9 & 1 \\
\hline Nausea & 8 & 2 & 6 \\
\hline Tachycardia & 8 & 5 & 3 \\
\hline Oliguria & 5 & 3 & 2 \\
\hline Vomiting & 5 & 2 & 3 \\
\hline Urinary retention & 3 & 2 & 1 \\
\hline Fall & 2 & 0 & 2 \\
\hline Confusion & 2 & 1 & 1 \\
\hline Urinary tract infection & 2 & 1 & 1 \\
\hline Polyuria & 1 & 1 & 0 \\
\hline Wound drainage & 1 & 1 & 0 \\
\hline $\begin{array}{l}\text { Acute gouty arthritis } \\
\text { great toe }\end{array}$ & 1 & 1 & 0 \\
\hline Hypertension & 1 & 1 & 0 \\
\hline Hand trauma & 1 & 0 & 1 \\
\hline Thrombocytopenia & 1 & 1 & 0 \\
\hline Dizziness & 1 & 0 & 1 \\
\hline $\begin{array}{l}\text { Gastroesophageal } \\
\text { reflux }\end{array}$ & 1 & 0 & 1 \\
\hline $\begin{array}{l}\text { Soft tissue swelling on } \\
\text { the left buttock }\end{array}$ & 1 & 1 & 0 \\
\hline Constipation & 1 & 0 & 1 \\
\hline Thrombocytopenia & 1 & 0 & 1 \\
\hline \multicolumn{4}{|l|}{ Major events } \\
\hline Pulmonary embolism & 2 & 1 & 1 \\
\hline $\begin{array}{l}\text { Systemic } \\
\text { inflammatory } \\
\text { response syndrome } \\
\text { (SIRS) }\end{array}$ & 1 & 0 & 1 \\
\hline Arrhythmia & 2 & 2 & 0 \\
\hline $\begin{array}{l}\text { Periprosthetic } \\
\text { fracture }\end{array}$ & 1 & 0 & 1 \\
\hline Vasovagal episode & 1 & 1 & 0 \\
\hline $\begin{array}{l}\text { Acute renal } \\
\text { insufficiency }\end{array}$ & 2 & 1 & 1 \\
\hline Total & 164 & 99 & 65 \\
\hline
\end{tabular}

Note: some patients had multiple events.
In our series, the rate of hospital adverse events in the first THA group was almost twice the one of the second. We speculate that the "experience" obtained during the first hip by patients as well as healthcare providers also played a significant role. The surgeon might be aware of previous hospital adverse events during the first hip and this knowledge might have positively affected the perioperative management of the second. The transfusion rates were not found significantly different between our two groups.

In conclusion, our data showed shorter LOS and fewer hospital adverse events following the second THA. These findings lead us to realize the positive role of "experience" on the perioperative outcomes of the second hip. A higher emphasis on preoperative education before the first THA is warranted. Patients might also be informed that the hospital experience during the second THA could be better than the one of the first hip when it comes to the occurrence of hospital adverse events, and that probably, they would be able to go home earlier when compared with the first one.

\section{Source of Funding}

The current investigation did not receive any specific grant from funding agencies in the commercial, public, or not-for-profit sectors.

\section{Conflict of Interest}

C.A.H. reports other from American Association of Hip and Knee Surgeons, Mid-American Orthopaedic Association, Musculoskeletal Infection Society, other from American Journal of Orthopedics, Journal of Arthroplasty, Journal of Hip Surgery, Journal of Knee Surgery, other from CD Diagnostics, Cymedica, Ferring Pharmaceuticals, OREF, Orthofix, Inc., Stryker, Zimmer, Lyfstone, personal fees and other from $\mathrm{KCI}$, other from PSI, outside the submitted work. J.C.S. reports other from Arthroplasty Today, other from Corin U.S.A., personal fees from DePuy, A Johnson \& Johnson Company, outside the submitted work. P.P. reports personal fees from Stryker, Zimmer, outside the submitted work. W.K.B. reports other from Beyond Limits, Capsico Health, Custom Orthopaedic Solutions, Sight Medical, other from DJO, Inc., NIH, Orthosensor, Third Frontier, other from Journal of Hip Surgery, personal fees from Exactech, Inc, Shukla Medical, personal fees and other from Peerwell, personal fees and other from Stryker, other from Thieme, personal fees and other from Zimmer, outside the submitted work.

\section{References}

1 Lindberg-Larsen M, Joergensen CC, Husted H, Kehlet H. Simultaneous and staged bilateral total hip arthroplasty: a Danish nationwide study. Arch Orthop Trauma Surg 2013;133(11): 1601-1605

2 Sah DRK, Sarfraz DAH. Comparative study of simultaneous and staged bilateral non-cemented total hip replacement in young active adults in terms of cost effectiveness and improvements in Harris hip score. Int J Orthop Sci 2018;4:935-938

3 Kim SC, Lim YW, Jo WL, et al. Surgical accuracy, function, and quality of life of simultaneous versus staged bilateral total hip arthroplasty in patients with Osteonecrosis of the femoral head. 
BMC Musculoskelet Disord 2017;18(01):266. Doi: 10.1186/ s12891-017-1605-2

4 Martin GR, Marsh JD, Vasarhelyi EM, Howard JL, Lanting BA. A cost analysis of single-stage bilateral versus two-stage direct anterior total hip arthroplasty. Hip Int 2016;26(01):15-19

5 Rasouli MR, Maltenfort MG, Ross D, Hozack WJ, Memtsoudis SG, Parvizi J. Perioperative morbidity and mortality following bilateral total hip arthroplasty. J Arthroplasty 2014;29(01):142-148

6 Kamath AF, Monteiro EL, Spranger A, Impellizzeri F, Leunig M. Simultaneous versus staged bilateral direct anterior total hip arthroplasty: are early patient-centered outcomes equivalent? Acta Orthop Belg 2016;82(03):497-508

7 Culler SD, Jevsevar DS, McGuire KJ, Shea KG, Little KM, Schlosser MJ. Predicting the incremental hospital cost of adverse events among Medicare beneficiaries in the comprehensive joint replacement program during fiscal year 2014. J Arthroplasty 2017;32(06):1732-1738.e1

8 Culler SD, McGuire KJ, Little KM, et al. Incremental hospital cost and length-of-stay associated with treating adverse events among Medicare beneficiaries undergoing cervical spinal fusion during fiscal year 2013 and 2014. Spine 2017;42(20):1578-1586

9 Higuera CA, Elsharkawy K, Klika AK, Brocone M, Barsoum WK. 2010 Mid-America Orthopaedic Association Physician in Training Award: predictors of early adverse outcomes after knee and hip arthroplasty in geriatric patients. Clin Orthop Relat Res 2011;469 (05):1391-1400

10 Pulido L, Parvizi J, Macgibeny M, et al. In hospital complications after total joint arthroplasty. J Arthroplasty 2008;23(06, Suppl 1):139-145

11 Guenther D, Schmidl S, Klatte TO, et al. Overweight and obesity in hip and knee arthroplasty: evaluation of 6078 cases. World J Orthop 2015;6(01):137-144

12 Schaeffer JF, Scott DJ, Godin JA, Attarian DE, Wellman SS, Mather RC III. The association of ASA class on total knee and total hip arthroplasty readmission rates in an academic hospital. J Arthroplasty 2015;30(05):723-727

13 Hart A, Antoniou J, Brin YS, Huk OL, Zukor DJ, Bergeron SG. Simultaneous bilateral versus unilateral total knee arthroplasty: a comparison of 30-day readmission rates and major complications. J Arthroplasty 2016;31(01):31-35

14 Morcos MW, Hart A, Antoniou J, Huk OL, Zukor DJ, Bergeron SG. No difference in major complication and readmission rates following simultaneous bilateral vs unilateral total hip arthroplasty. J Arthroplasty 2018;33(08):2541-2545

15 Sutton JC III, Antoniou J, Epure LM, Huk OL, Zukor DJ, Bergeron SG. Hospital discharge within 2 days following total hip or knee arthroplasty does not increase major-complication and readmission rates. J Bone Joint Surg Am 2016;98(17):1419-1428 